\title{
Studying the Effectiveness of Combination Therapy (Based on Executive Function and Sensory Integration) Child-Centered on the Symptoms of Attention Deficit/Hyperactivity Disorder (ADHD)
}

\author{
Fatemeh Salami ${ }^{1}$, Hassan Ashayeri ${ }^{2}$, Mahnaz Estaki ${ }^{1}$, Valiollah Farzad $^{1} \&$ Roya Koochak Entezar $^{1}$ \\ ${ }^{1}$ Psychology Department, Islamic Azad University, Tehran Central Branch, Iran \\ ${ }^{2}$ Iranian University of Medical Science, Iran \\ Correspondence: Fatemeh Salami, Psychology Department, Islamic Azad University, Tehran Central Branch, \\ Iran. E-mail: fanos1386@yahoo.com
}

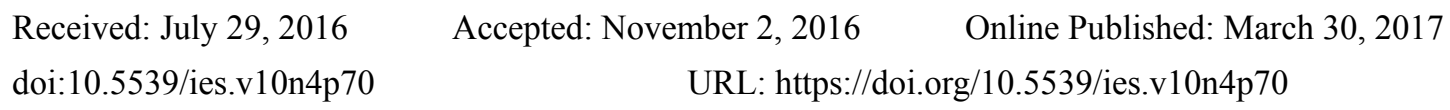

\begin{abstract}
The aim of the present study is to examine the effectiveness of combination therapy based on executive function and sensory integration child-centered on ADHD. For this purpose, from among all first, second and third grade primary school students in Shiraz, 40 children were selected. The selected students were randomly assigned in two groups of experimental $(n=20)$ and control group $(n=20)$ by random method through internet call from Education site, and by Clinical Interview, implementation of CSI-4 parent form, and according to the criteria for entry and after matching. Combination therapy based on executive function and sensory integration includes 24 sessions of an hour and a half, in groups of five in four groups of children that was held three times a week. Pre-test and post-test in both groups was performed using CSI-4 parent form. Data obtained were analyzed using analysis of covariance and SPSS software. The results showed that combination therapy based on executive function and sensory integration child-centered reduces attention deficit and hyperactivity.
\end{abstract}

Keywords: combination therapy, executive function, sensory integration, attention deficit/hyperactivity disorder

\section{Introduction}

ADHD is a nerve-behavioral and developmental disorder of childhood that 3 to 7 percent of school-age population is affected by the disorder (Barkley, 2006). The consequences of this disorder affect different aspects of functioning and normal development of the individual. In fact, children with the disorder, besides suffering various behavioral problems (such as low self-esteem, aggression and learning disability) (Bell, 2011; Pliszika, 2009), often suffer from at least one comorbid disorder (Barnard-Brak, 2011). Wide spread, behavioral consequences, and the existence of comorbid disorders have made the treatment of these children a complex challenges (Pelham and Fabiano, 2008). In theoretical and research perspectives, the multiple role of biological, neurological, psychological, and environmental causes has been paid special attention to, so that this disorder is of the disorders that has received various theoretical perspectives to itself (Berkley, 1997), but, up to now, no unique treatment has been developed for optimal face with this disorder (Rapport \& Chung, 2001). In recent years, according to studies based on neuroimaging, it is shown that children with ADHD have problems in the cerebellum and frontal piece with the basic functions in planning, organizing, decision-making, perception of time, inhibition and are thinking (Hynd et al., 1991). By reviewing studies of neuropsychological studies related to functioning of frontal lobe in children with ADHD, Barkley et al. (1992) found that the ability to inhibit the response is done through frontal lobes, particularly the orbitofrontal areas, medial frontal, and numerous joints with striatum. By reviewing research related to executive functions in children with ADHD, Pennington and Ozonoff (1996) found that in 15 to 18 studies, people with this disorder compared to healthy people, in one or more of indices of executive functions have had significant differences, and some degree of frontal lobe dysfunction in these children have been reported. Many studies have referred to behavioral inhibition problems of people with ADHD (Semrud-Clikman et al., 2000 Willcatt et al., 2001). Using brain-imaging technology has found the same abnormalities in the three areas of the brains of people with ADHD: prefrontal lobes, frontal lobes, basal ganglia (especially the tail core and globus pallidus), cerebellum, and corpus callosum (Nigg et al., 2002). The results of the study by Bush (2010) show that the pre-frontal lobe dysfunction causes impulsivity 
and/or hyperactivity and self-control problems connected with executive functions, and pre-frontal lobe dysfunction also causes inappropriate inhibitory actions or improper behavior. The right hemisphere dysfunction and damage to the basal ganglia, frontal lobe, and prefrontal brain reduces the intentional motor activity, sensory processing disorders, and hyperactivity (Ayres, 1979). Research results show that motor problems are a strong predictor of poor self-esteem in children with ADHD (Skinner \& Piek, 2001). According to the studies by Kooistra (2005), 30-70\% of children with ADHD have motor control problems that may be associated with neurobehavioral development. The results of this study showed that motor deficits in school-age children make them pron to concerns over the problems in social competition and academic success. Research by Parush et al. (2007) also shows the weak and poor sensory integration and sensory function and prevention of excessive movement in children with ADHD resulting in balance problems. Dalaney (2008) introduces twelve signs of the symptoms of sensory processing disorders, including very high or low level of activity, impulsivity, extreme sensitivity to touch, distractibility, and so on that can be seen in people with ADHD.

Based on neuroimaging studies, Qiu et al. (2009) revealed that not only the prefrontal, but also basal ganglia affect purposeful movements in children with ADHD. Davlin et al. (2011) suggest that hyperactivity is the most obvious problem in children with ADHD.

The right hemisphere dysfunction, damage to the basal ganglia (due to the relationship between muscular movement control and voluntary movements), frontal lobe, and prefrontal brain decrease intentional motor activity and lead to hyperactivity that based on the definition by Ayres (1979), it is the sensory-theoretical integrity of the relationship between brain and behavior. Davlin believes that sensory integration process brings about the necessary context for correct sensory and motor understanding and thus appropriate motor responses. The results of the study by Shimizu et al. (2014) suggest that children with ADHD, compared to children in the control group, have significant problems in the process and sensory modulation behavioral and emotional responses. Therefore, understanding the sensory-process problems in these children is important and can be of help in symptomatology of this disorder. Treatment of ADHD is mainly based on medication, parent-centered psychoeducational interventions, child-centered psychoeducational interventions, and hybrid psychoeducational interventions, parent, and children training (Kazdin and Whitley, 2006). Child-centered psychoeducational interventions include activities based on the etiology of the disorder and based on theories put forward the treatment takes shape. The existing problems in the executive functions of the brain and sensory integration have led to formation of treatments based on these two theories, and many studies support this theory and treatment plans. Development and training of executive functions play a key role in the development of academic and social abilities of children (Hughes et al., 1998; Semrud-Clikman et al., 2005). Teaching executive functions to primary school children with ADHD type C improves the reduction of symptoms of ADHD and executive functions significantly statistically improve (Papazian et al., 2009). Teaching problem solving is an effective cognitive therapy to improve executive function in children with this disorder (Kray et al., 2011). Sensory integration interventions reduce impulsivity and anger management in children with ADHD (Vargas \& Camilli, 1999). Bundy and Murray (2002) consider assignments-based therapeutic approach as based on- sub-cortical activation- sensory and coordination approach that can increase body response status, bilateral integration, eye movements, and balance. The results of the study by Ibrahimi (2013) showed that sensory-motor integration intervention with an emphasis on proprioceptive and vestibular senses (twice a week and during 12 sessions of two hours) significantly improved ADHD. Access to treatment with the most effectiveness encourages the researchers for further studies, and as studies suggest multi-dimensional problems of ADHD is possible by incorporating some treatment approaches (Simpson et al., 2011). Due to the effectiveness of the treatments based on executive functions of the brain and sensory integration, this study plans to study the effectiveness of combining two therapeutic methods "executive functions" and "sensory integration," both of which are treatments with considerable research evidence and emphasize neurocognition factors.

\subsection{The Main Research Question}

Does combination -therapy, based on executive functions and sensory integration child-centered, affect ADHD?

The hypotheses of the study include:

- Combination-therapy, based on executive functions and sensory integration child-centered, affects attention deficit syndrome in children with ADHD

- Combination-therapy, based on executive functions and sensory integration child-centered, affects symptoms of hyperactivity / impulsivity in children with ADHD. 


\section{Method}

The population of this study includes all primary school students of first, second, and third grade with ADHD in Shiraz. In this study, from among the four districts of Shiraz, District 4 was selected randomly. To include a greater volume of the population in the program, the researcher held training sessions for managers and interfaces of boys' primary schools of District 4 Shiraz to inform them of the research project. then to include Education Site and the principals of boys' primary school District 4 in the intervention program, through calls Internet calls, the researcher informed them. By clinical interview, performing to CSI-4 parent form, and according to the inclusion criteria [average intelligence range (can use school usual education without specific problems), non-use of drugs, non-disability (blindness, deafness and disabilities physical), and the absence of other psychological diseases], they were selected and after matching for age, parental education, and lifestyle (living with both parents or one parent), 40 children were placed in two groups of control $(n=20)$ and experiment $(\mathrm{n}=20)$.

The sample group was randomly assigned to an experimental group (children) that receives the independent variable and a control group that do not get any assignments. The independent variable in this study includes the hybrid therapy based on executive functions and sensory integration, including 24 sessions of one hour and a half, three times a week for 2 months in form of four groups of five people. Activities include five types of activities, of which three are in the areas of executive function (1- concentration, 2- working memory, and 3behavior inhibition) and two types of sensory integration (4-stimulation of tactile system, 5- Simulation of deep system), which were done according to collaboration and acceptance of children.

\subsection{Activities of Increasing Concentration}

walking with lighted candles in hand be careful not to go off, blowing the candle flame but not extinguish it, walking with a book on the head and not letting it fall down, walking with a spoon in the mouth with a ball in it not letting it fall down, giving a bell to the child to walk with and not let it sound, walking slowly on a straight line as much possible, transferring rice with a small spoon from a bowl to another bowl.

\subsection{Activities to Improve Working Memory}

saying numbers from three and more and repetition by children, putting words card in front of him for 2 minutes, and then turning them over to see how many words he remembers, looking at the word cards then removing one (now which word is missing?), leaving objects on the table and taking them (saying what he remembers), telling a few words and then asking the child to make sentences with the words he remembers.

\subsection{Activities for Increasing Behavior Inhibition}

asking questions with yes no answers, but the opposite answer must be given, sitting down and standing up reversely and directly with hearing one jump up, two bringing the hand down, and three lifting the leg, playing crow jump, saying the words and asking the kids to clap as many times as the dot of the words, drawing pictures with the dominant hand and tapping the table with the other hand, statue game: when the word statue is said, the child should stand still.

\subsection{Activities for Stimulation of Tactile System}

a light touch, using sponge or feather on face, crawl, crawling, walking on hips, rolling the ball back in the prone position, scrubbing the whole body, performing arts activities such as finger painting, play, moving on the ball back and forth, touch the people face and recognizing them, touching various objects.

\subsection{Activities for Stimulation of Deep System}

Transportation, crumpling the newspaper, walking on a stick, students' turning around himself and repeating it three times, child's walking with his hands, crawling, passing under a rope that is about 30 to $40 \mathrm{~cm}$ above ground, walking on the toe and heel, walking with a glass of water, bouncing with one leg.

Twenty-four hours before and after treatment sessions, in order to obtain the necessary information and data, Child Symptom Inventory (CSI-4) of parent form was run. CSI-4 was developed in 1984 by Sprafkin and Gadow based on DSM-III classification to screen behavioral and emotional disorders of children of 5 to 12 years old and in 1994 along with the fourth edition, DSM- IV was revised. This questionnaire is one of the most comprehensive grading scales of abnormal behavior that has a list form for parent and teacher scored at a 4-point scale of never, sometimes, often and most of the times (Mohammad-Ismail, 2004). CSI-4 has two parent and teacher forms. Parents form has 112 questions designed for 11 major groups and 1 additional group of behavioral and emotional disorders, and teacher form has information from the academic setting and educational function of children with 87 questions designed for screening nine emotional and behavioral disorders (Gadow \& Sprafkin, 
1994).

In this study, the first group of disorders (Attention Deficit / Hyperactivity group), which contains 18 questions was considered, first nine questions assess attention deficit and next nine question assess hyperactivity.

Two scoring methods are designed for CSI-4: the screening cut of score method and the symptom severity score method. The screening cut of score method is scored based on never $=0$ sometimes $=0$, often $=1$, and most of the time $=1$, and symptom severity score method is scored on a 4-point scale of never $=0$, some sometimes $=1$, often $=2$, and most of them $=3$, scored (Mohammad-Ismail, 2004). In this study, the second way of scoring is used. In the study by Gadow and Sprafkin (1994), done on the form SLUG (CSI-3R), the validity of the questionnaire for 36 children with emotional disorders with test re-test method with an interval of 6 weeks for ADD disorder with or without hyperactivity, defiance disorder, conduct disorder with and without aggression was reported from 0.7 to 0.89 . In this study, the Cronbach's alpha for attention deficit hyperactivity was obtained as 0.67 and 0.66 for hyperactivity.

\section{Results}

The descriptive findings:

Table 1. Descriptive information of the variables separately for process and group

\begin{tabular}{cccccccc}
\hline Group & Variable & Level & Frequency & Mean & The standard deviation & Minimum & Maximum \\
\hline Experimental group & Attention Deficit & Pre-test & 20 & 0.6521 & 2.43 & 17 & 27 \\
\hline & & Post-test & 20 & 1.900 & 2.15 & 4 & 13 \\
\hline & Hyperactivity & Pre-test & 20 & 21.45 & 2.60 & 15 & 26 \\
\hline & & Post-test & 20 & 9.85 & 3.01 & 4 & 14 \\
\hline Control & Attention Deficit & Pre-test & 20 & 20.05 & 2.37 & 16 & 25 \\
\hline & & Post-test & 20 & 18.20 & 2.21 & 14 & 22 \\
\hline & Hyperactivity & Pre-test & 20 & 20.25 & 2.67 & 16 & 25 \\
\hline & & Post-test & 20 & 19.60 & 2.46 & 14 & 23 \\
\hline
\end{tabular}

To evaluate the hypotheses, analysis of covariance was used, so first the presumptions of this test are examined. Results of Table 1 show the significance level values of all variables over 0.05 so data follow a normal distribution

Table 2. Table of normality test of attention deficit variable in two steps

\begin{tabular}{ccc}
\hline Variables & Kolmogorov-Smirnov & The significance level \\
\hline Pre-test of attention deficit & 0.50 & 0.96 \\
\hline Post-test of Attention Deficit & 1.06 & 0.20 \\
\hline
\end{tabular}

Given that the use of parametric test has the assumptions that scores distribution is normal, in other words, the condition of equality of variances should be established between groups, so Levene's test was used. Table 3 shows that Levene's test in post-test of the attention deficit is not significant, due to the lack of significance, variances are equal. This is significant because it confirms the reliability of the upcoming results.

In attention deficit variable, significance value in the variable is level greater than ( $\mathrm{P}>0.05)$, so with $95 \%$ level of confidence the condition for equality of variances is established and covariance analysis is allowed to be used.

Table 3. Levene's test to determine equality of variances

\begin{tabular}{lcccc}
\hline Variables & F & The degree of freedom 1 & The degree of freedom 2 & The level of significance \\
\hline Attention Deficit post-test & 2.10 & 1 & 38 & NS (0.15) \\
\hline
\end{tabular}

In addition to Levene's test in Table 4, it can be seen that $\mathrm{F}$ calculated for pre-test group interaction is not significant, in the sense that the relationship between the dependent variable (Attention Deficit post-test) and covariate (pre-test of Attention Deficit) is the same for all experimental groups as the regression line of all is parallel. Thus, the presumption of homogeneity of the slope of the regression is observed 
Table 4. Regression homogeneity test for the use of covariance (Attention Deficit)

\begin{tabular}{lccccc}
\hline The level of significance & $\mathrm{F}$ & The mean squares & Degrees of freedom & Sum of squares & Resource change \\
\hline $\mathrm{NS}(0.14)$ & 2.24 & 241.73 & 2 & 483.46 & Group * pre-test \\
\hline
\end{tabular}

According to Table 5, the results of post-test of attention deficit of children according to the type of group (P $\leq$ $0.001, \mathrm{df}=1, \mathrm{~F}=174.63$ ) were significant. Thus, the experimental group compared to the control group had reduction in attention deficit. The effect of intervention of the independent variable (combined teaching of executive functions and integrity) is 0.82 . This means that $82 \%$ of the variance of post-test scores of attention deficit has been due to the impact of educating children. This means that the integrated executive functions and the integrity education to children reduce children's attention deficit disorder and the first hypothesis is confirmed.

Table 5. Analysis of covariance to assess the effect of combined executive functions and sensory integration training to children with attention deficit

\begin{tabular}{lcccccc}
\hline Change source & Sum of squares & Degree of freedom & Mean square & $\mathrm{F}$ & Level of significance & Eta square \\
\hline Pre-test & 80.71 & 1 & 80.71 & 29.78 & $\mathrm{P}<0.05$ & 0.45 \\
\hline Group & 473.35 & 1 & 473.35 & 174.63 & $\mathrm{P}<0.05$ & 0.82 \\
\hline
\end{tabular}

The study the second hypothesis, there was needed to use the statistical method of analysis of covariance, so the presumptions of this test are examined. Results of Table 6 show significance level values of all variables over 0.05 , so data follow a normal distribution.

Table 6. Table of normality test of hyperactivity variable in two steps

\begin{tabular}{lcc}
\hline Variables & Kolmogorov-Smirnov & Significant level \\
\hline Pre-test of hyperactivity & 0.82 & 0.51 \\
\hline Post-test of hyperactivity & 0.88 & 0.40 \\
\hline
\end{tabular}

Given that the use of parametric test has the assumptions that scores distribution is normal, in other words, the condition of equality of variances should be established between groups, so Levene's test was used. Table 7 shows that Levine's in post-test of the hyperactivity is not significant, due to the lack of significance, variances are equal. This is significant because it confirms the reliability of the upcoming results.

In hyperactivity variable, significance value in the variable is level greater than ( $\mathrm{P}>0.05)$, so with $95 \%$ level of confidence the condition for equality of variances is established and covariance analysis is allowed to be used.

Table 7. Levene's test for equality of variances

\begin{tabular}{lcccc}
\hline Variables & F & The degree of freedom 1 & The degree of freedom 2 & The level of significance \\
\hline Post-test of hyperactivity & 2.81 & 1 & 38 & NS $(0.07)$ \\
\hline
\end{tabular}

In addition to Levene's test in Table 8, it can be seen that $\mathrm{F}$ calculated for pre-test group interaction is not significant, in the sense that the relationship between the dependent variable (Hyperactivity post-test) and covariate (pre-test of Hyperactivity) is the same for all experimental groups as the regression line of all is parallel. Thus, the presumption of homogeneity of the slope of the regression is observed.

Table 8. Regression homogeneity test for the use of covariance (Hyperactivity)

\begin{tabular}{cccccc}
\hline Change source & Sum of squares & Degree of freedom & Mean square & F & Level of significance \\
\hline Group pre-test & 842.12 & 2 & 421.06 & 1.16 & NS $(0.29)$ \\
\hline
\end{tabular}

According to Table 9, the results of post-test of hyperactivity of children according to the type of group ( $\mathrm{P} \leq$ $0.001, \mathrm{df}=1, \mathrm{~F}=120.32$ ) were significant. Thus, the experimental group compared to the control group had 
reduction in hyperactivity. The effect of intervention of the independent variable (combined teaching of executive functions and integrity) is 0.76 . This means that $76 \%$ of the variance of post-test scores of hyperactivity has been due to the impact of educating children. This means that the integrated executive functions and the integrity education to children reduce children's hyperactivity disorder.

Table 9. Analysis of covariance to assess the effect of combined executive functions and sensory integration training to children with hyperactivity

\begin{tabular}{lcccccc}
\hline Change source & Sum of squares & Degree of freedom & Mean square & $\mathrm{F}$ & Level of significance & Eta square \\
\hline pre-test & 47.69 & 1 & 47.69 & 7.36 & $\mathrm{P}<0.05$ & 0.17 \\
\hline Group & 779.37 & 1 & 779.37 & 120.32 & $\mathrm{P}<0.05$ & 0.76 \\
\hline
\end{tabular}

\section{Discussion}

The results of this study showed that combined therapy of executive function and sensory integration to children reduces attention deficit and hyperactivity of the children. The goal of treatment of this disorder is to enable children to overcome problems encountered during their life. Treatment should involve multilateral efforts, although many treatments have created significant changes in child mental state, only a few could really treat the child. Most of these children again manifest symptoms of the problem and need treatment follow up; treatment based on etiology increases the likelihood of its success. In recent years, according to studies based on neuroimaging, it has been shown that children with ADHD have problems in the cerebellum and frontal piece with the basic functions of planning, organizing, decision-making, perception of time, inhibition and thinking (executive functions of the brain) (Barkley, 2006). Moreover, the same abnormalities have been observed in the three regions of the brains of people with ADHD: the prefrontal lobes, frontal lobes, basal ganglia (in particular, caudal nucleus and globus pallidus), cerebellum, and corpus callosum (Nigg et al., 2002). Accordingly, treatment designed based on the defects of executive functions and sensory integration has stronger theoretical foundations. Since studies suggest that reduction of multi-dimensional problems of ADHD is feasible to be done through, incorporating some treatment approaches (Simpson et al., 2011). Thus due to problems in executive functions and sensory integration, the present research is trying to cause stimulation and neuroplasty of more and wider areas of the brain by doing activities that have a direct impact on attention, working memory, behavioral inhibition (components of executive functions of the brain), and sensory problems, problems with balance (sensory integration components). This is while most studies have examined only one of these two issues and designed activities related to the same defect. The results of this study are consistent with the results of the research by Papazian et al (2009), which suggest that teaching executive functions to primary school children with ADHD type $\mathrm{C}$ may improve symptoms of ADHD. Moreover, teaching executive functions plays a key role in the development of social and academic abilities of children (Hughes et al., 1998; Klingberg et al., 2002). The results of this study also suggest that sensory integration intervention reduces inappropriate behaviors, improves concentration, reduces impulsivity in children with ADHD that are in line with the results of Hadlre (1997); Stratton and Gailfus (1998); Vargas and Comili (1999); Hay et al. (2005); Arnold et al. (2008); Davlin et al. (2011) and Ibrahami (2013).

\section{Limitations}

This study had some limitations. The experimental design with one test group makes generalization of the results difficult. As a result, it is recommended that in future studies, experimental projects with higher generalization be used.

\section{Acknowledgments}

Hereby, Education of District Four Shiraz, primary schools of this district, and parents of children with ADHD are thanked for their cooperation.

\section{References}

Arnold, L. E., Crowl, L., Bozzolo, H., Peruggia, M., Ramadan, Y., Bornstein, R., . . Clark, D. L. (2008). Vestibular stimulation for ADHD: randomized controlled trial of comprehensive motion apparatus. Journal of Attention Disorder, 11(5), 599-611. https://doi.org/10.1177/1087054707311042

Ayres, A. J., \& Robbins, J. (1979). Sensory integration and the child (Vol. 12). Los Angeles: Western Psychological Services.

Barkley, R. A. (1997). Behavioral inhibition, sustained attention, and executive function: Construction a unifying 
theory of ADHD. Psychological Bulletin, 121, 65-94. https://doi.org/10.1037/0033-2909.121.1.65

Barkley, R. A. (2006). Attention-deficit/Hyperactivity disorder: A handbook for diagnosis and treatment (3rd ed.). New York: Guilford Press.

Barkley, R. A., Grodzinsky, G., \& DuPaul, G. J. (1992). Frontal lobe functions in attention deficit disorder with and without hyperactivity: A review and research report. Journal of abnormal child psychology, 20(2), 163-188. https://doi.org/10.1007/BF00916547

Barnard-Brak, L., Sulak T. N., Fearon D. D. (2011). Coexisting disorders and academic achievement among children with ADHD. Journal of Attention Disorders, 15(6), 506-15. https://doi.org/10.1177/1087054710369667

Bell, A. S. A. (2011). Critical review of ADHD diagnostic criteria: What to address in the DSM-V. Journal of Attention Disorders, 15(1), 3-10. https://doi.org/10.1177/1087054710365982

Bundy, A. C., \& Murray E. A. (2002). Sensory integration, A Jean Ayres revisited. In A. C. Bundy, S. Lane, E. A. Murray (Eds.), Sensory Integration, Throry and Practice (2nd ed. pp. 5-12). FA Davis Company.

Bush, G. (2010). Attention-deficit/hyperactivity disorder and attention networks. Neuropsychopharmacology, 35, 278-300. https://doi.org/10.1038/npp.2009.120

Delaney, T. (2008). The Sensory Processing Disorder Answer Book: Practical Answers to the Top 250 Questions Parents Ask. Sourcebooks, Inc.

Devlin, S., Healy, O., Leader, G., Hughes, B. M. (2011). Comparison of behavioral intervention and sensory-integration therapy in the treatment of challenging behavior. J Autism Dev Disord, 41(10), 1303-20. https://doi.org/10.1007/s10803-010-1149-x

Ebrahimi, M., Varnoosfaderani, A, Haghgoo, H. A., Pourmohamad-Rezatajrishi, M., \& Danaeefard, F. (2013). The effectiveness of sensory integration activities-move on symptoms of attention deficit-hyperactivity. Research in Rehabilitation Sciences, 9(2), 220-231.

Gadow, K. D., \& Sprafkin, J. (1994). Child Symptom inventories manual. Stony Brook,Ny: Checkmates Plus.

Hadler, P. (1997). Chiroprctic Farmington: handle family chiropactic. U.S.A: North western college.d. Philadelphia: Davis Company.

Hay, L., Bard, C., Ferrel, C., Olivier, I., \& Fleury, M. (2005). Role of proprioceptive information in movement programming and control in 5 to 11-year old children. Hum Mov Sci, 24(2), 139-54. https://doi.org/10.1016/j.humov.2005.05.002

Hughes, H. C., Nelson, M. D., \& Aronchick, D. M. (1998). Spatial characteristics of visual-auditory summation in human saccades. Vision research, 38(24), 3955-3963. https://doi.org/10.1016/S0042-6989(98)00036-4

Hynd, G. W., Semrud-Clikeman, M., Lorys, A. R., Novey, E. S., Eliopulos, D., \& Lyytinen, H. (1991). Corpus callosum morphology in attention deficit-hyperactivity disorder: morphometric analysis of MRI. Journal of Learning Disabilities, 24(3), 141-146. https://doi.org/10.1177/002221949102400302

Kazdin, A. E. Whitley, M. K. (2006). Comorbidity, casecomplexity, and effects of evidence-based treatment for children referred for disruptive behaviour. Journal of Consulting and Clinical Psychology, 74, 455-67. https://doi.org/10.1037/0022-006X.74.3.455

Klingberg, T., Forssberg, H., \& Westerberg, H. (2002). Training of working memory in children with ADHD. Journal of clinical and experimental neuropsychology, 24(6), 781-791. https://doi.org/10.1076/jcen.24.6.781.8395

Kooistra, L., Crawford, S., Dewey, D., Cantell, M., \& Kaplan, B. J. (2005). Motor Correlates of ADHD Contribution of Reading Disability and Oppositional Defiant Disorder. Journal of Learning Disabilities, 38(3), 195-206. https://doi.org/10.1177/00222194050380030201

Kray, J., Karbach, J., Haenig, S., \& Freitag, C. (2011). Can task-switching training enhance executive control functioning in children with attention deficit/hyperactivity disorder? Frontiers in human neuroscience, 5.

Mohammad-Ismail, E., Alipour, A. (2004). A preliminary study to determine the validity, reliability, and cutting parts of disorder Child Symptom Inventory (CSI-4). Publisher: Exceptional Children Research Institute, Department of Education exceptional country.

Nigg, J. T., Blaskey, L. G., Huang-Pollock, C. L., \& Rappley, M. D. (2002). Neuropsychological executive functions and DSM-IV ADHD subtypes. Journal of the American Academy of Child \& Adolescent 
Psychiatry, 41(1), 59-66. https://doi.org/10.1097/00004583-200201000-00012

Papazian, O., Alfonso, I., Luzondo, R. J., \& Araguez, N. (2009). [Training of executive function in preschool children with combined attention deficit hyperactivity disorder: A prospective, controlled and randomized trial]. Revista de neurologia, 48, S119-22.

Parush, S., Sohmer, H., Steinberg, A., \& Kaitz, M. (2007).Somatosensory function in boys with ADHD and $\begin{array}{llll}\text { tactile defensiveness. Physiology } \& \text { Behavior, } & \text { 90(4), 553-558. }\end{array}$ https://doi.org/10.1016/j.physbeh.2006.11.004

Pelham, W. E., \& Fabiano, G. A. (2008). Evidence-based psychological treatment for Attention-deficit hyperactivity disorder: An update. Journal of Clinical Child and Adolescent Psychology, 34, 184-214. https://doi.org/10.1080/15374410701818681

Pennington, B. F., \& Ozonoff, S. (1996). Executive function and developmental psychopathology. Journal of Child Psychology and Psychiatry, 37, 51-87. https://doi.org/10.1111/j.1469-7610.1996.tb01380.x

Pliszka, S. R. (2009). ADHD and Comorbid Disorders Psychosocial and Psychopharmacological Intervention. New York: The Guilford Press.

Qiu, A., Crocetti, D., Adler, M., Mahone, E. M., Denckla, M. B., Miller, M. I., \& Mostofsky, S. H. (2009). Basal ganglia volume and shape in children with attention deficit hyperactivity disorder. Am J Psychiatry, 166, 74-82. https://doi.org/10.1176/appi.ajp.2008.08030426

Rapport, M. D., \& Chung, K. (2001). A Conceptual Model of Child Psychopathology: Implication for Understanding ADHD and Treatment Efficacy. Journal of Clinical Child Psychology, 34, 48-58. https://doi.org/10.1207/S15374424JCCP3001_6

Semrud-Clikeman, M. (2005). Neuropsychological aspects for evaluating learning disabilities. Journal of Learning Disabilities, 38(6), 563-568. https://doi.org/10.1177/00222194050380061301

Semrud-Clikman, M., Steingard, R. J., Filipek, P., Biederman, J., Bekken, K., \& Renshaw, P. F. (2000). Using MRI to examine brain-behavior relationships in males with attention deficit disorder with hyperactivity. Journal of the American Academy of Child and Adolescent Psychiatry, 39, 477-484. https://doi.org/10.1097/00004583-200004000-00017

Shimizu, V. T., Bueno, O. F., \& Miranda, M. C. (2014). Sensory processing abilities of children with ADHD. Brazilian journal of physical therapy, 18(4), 343-352. https://doi.org/10.1590/bjpt-rbf.2014.0043

Simpson, H. A., Jung, L., \& Murphy, T. K. (2011). Update on attention-deficit/hyperactivity disorder and tic disorders: a review of the current literature. Current psychiatry reports, 13(5), 351-356. https://doi.org/10.1007/s11920-011-0223-1

Skinner, R. A., \& Piek J. P. (2001). Psychosocial implications of poor motor coordination in children and adolescents. Hum Mov Sci, 20, 73-94. https://doi.org/10.1016/S0167-9457(01)00029-X

Stratton, J., \& Gailfus, D. (1998). A new approach to substance abuse treatment: Adolescents and adults with $\begin{array}{lllll}\text { ADHD. Journal of substance abuse treatment, } & \text { 15(2), 89-94. }\end{array}$ https://doi.org/10.1016/S0740-5472(97)00026-3

Vargas, S., \& Camilli, G. (1999).A meta-analysis of research on sensory integration treatment. American Journal of Occupational Therapy, 53(2), 189-198. https://doi.org/10.5014/ajot.53.2.189

Willcatt, E. G., Chhabildas, N., \& Pennington, B. F. (2001). Validity of the DSM-IV subtypes of ADHD. ADHD Report, 9(1), 2-5. https://doi.org/10.1521/adhd.9.1.2.16970

\section{Copyrights}

Copyright for this article is retained by the author(s), with first publication rights granted to the journal.

This is an open-access article distributed under the terms and conditions of the Creative Commons Attribution license (http://creativecommons.org/licenses/by/4.0/). 